\title{
DEL TURISMO INMOBILIARIO AL TURISMO DE NATURALEZA ¿CAMBIO DE MODELO O CAMBIO DE DISCURSO? EL CASO DE NOJA, UN MUNICIPIO EN LA COSTA CANTÁBRICA
}

\author{
Carmen Gil de Arriba \\ Universidad de Cantabria
}

\section{RESUMEN}

En este artículo se aborda un tipo de relaciones que, a priori, parecen difíciles de conciliar, las que se plantean entre el llamado turismo residencial (denominación bajo la que a menudo se esconden los intereses del sector inmobiliario) y el turismo de naturaleza en espacios litorales. Tras un encuadre de la problemática, hemos optado por un caso de estudio que reúne buena parte de los rasgos que definen este tipo de espacios turísticos: por un lado, fuerte crecimiento inmobiliario, expansión urbana, alto nivel de permisibilidad urbanística y escasa adecuación del modelo a las condiciones ambientales; por otro, entorno de elevado valor ecológico y declaración como espacio natural protegido. Además, este caso de estudio tiene también cualidades específicas o distintivas, entre las que se encuentra su localización en la costa cantábrica, donde estos procesos han sido menos estudiados que en el Mediterráneo, y su proximidad al área metropolitana de Bilbao que ejerce como centro urbano de influencia. A partir del repaso de todas estas características, analizamos si la puesta en valor turístico de un espacio protegido supone un cambio real del modelo residencial e inmobiliario seguido hasta ahora o simplemente la adaptación a unas nuevas condiciones de mercado.

Palabras clave: turismo residencial, segunda residencia, recursos territoriales, espacios naturales, turismo ornitológico.

Fecha de recepción: 13 de abril de 2018

Fecha de aceptación: 5 de noviembre de 2018

Departamento de Geografía, Urbanismo y Ordenación del Territorio. Universidad de Cantabria. Avda. de Los Castros, s/n. 39005 SANTANDER (España). E-mail: carmen.gil@unican.es 


\title{
From real estate tourism to nature related tourism. Change of model or a shift in the discourse? The case of Noja (Cantabria, Spain)
}

\begin{abstract}
This article studies a relationship, which a priori appears incompatible, between so called residential tourism (a name under which real estate interests lie) and tourism related to nature in coastal areas. After establishing a theoretical and methodological framework, a case study is analysed: the municipality of Noja in the North of Spain. This case combines most of the features that define this area type. On the one hand, strong real estate growth, a high level of urban sprawl and speculation, and limited control and adjustment of the model to environmental conditions. On the other hand, it is an ecologically valuable, protected, natural area. Moreover, this particular case study has specific or distinctive qualities, such as a geographical location on the Cantabrian coast where few studies have been carried out, unlike the Mediterranean coast, and proximity to the influential metropolitan area of Bilbao. Following a review of all of the above characteristics, we analyse whether the implementation of tourist values in a protected space represents a major change in the residential and real estate model pursued to date or whether these changes are just a gradual adjustment to new market conditions.
\end{abstract}

Keywords: residential tourism, second residence, tourist territorial resources, protected natural areas, ornithological tourism.

\section{INTRODUCCIÓN: TURISMO LITORAL Y ESPECIALIZACIÓN RESIDEN- CIAL, UN FENÓMENO ANTIGUO CON RASGOS NUEVOS}

A partir de mediados del siglo XX, el desarrollo de actividades turísticas en distintas áreas litorales españolas se ha plasmado en un considerable proceso de urbanización y edificación, muy relacionado con la construcción de segundas residencias y de viviendas para uso turístico, siguiendo diferentes tipologías morfológicas y fórmulas de producción y comercialización. Este fenómeno, habiendo sido estudiado sobre todo para el litoral mediterráneo, ha resultado un modelo generalizado en todo el país, desarrollado y propagado de unas zonas a otras durante décadas de crecimiento turístico e inmobiliario ${ }^{1}$, del que han derivado importantes consecuencias económicas, urbanísticas y medioambientales, visibles hoy en día en el conjunto de los espacios turísticos costeros españoles ${ }^{2}$. De hecho, los espacios turísticos litorales españoles han sido de los más implicados en el denominado ciclo expansivo financiero-inmobiliario (Murray, 2015, p.93 y sigs.)

1 Por solo mencionar algunos trabajos publicados en las dos últimas décadas, cabe citar a Mateu (2003), Huete y Mazón (2005), Mazón y Aledo (2005), Serrano (2007), Navarro (2008), Ponce (2010), Vera y Baños (2010) y Capdepón (2016).

2 Entre los años 2000 a 2013, la organización ecologista Greenpeace vino realizando el informe anual titulado Destrucción a Toda Costa, alertando sobre los problemas ocasionados por la llamada burbuja inmobiliaria y la construcción masiva en el litoral español, a partir del análisis a escala municipal de la ocupación del suelo en los 500 primeros metros de costa y mediante el uso de imágenes satélite. En 2014, la organización renunció, por motivos de reajuste presupuestario, a proseguir con la publicación de dichos informes. 
Por otra parte, este proceso de especialización turístico-residencial de los municipios litorales españoles, que se hace masivo a partir de los años setenta y ochenta, cuenta con precedentes históricos, anteriores al turismo de masas, como ya fuera señalado por Vera (1984) en un trabajo pionero dedicado al municipio de Torrevieja ${ }^{3}$.

Aunque inicialmente esta vinculación directa entre turismo y sector inmobiliario fuese entendida socialmente como un modelo económico de éxito (Mazón y Aledo, 2004), en la actualidad este hecho complejo de la residencialización $n^{4}$ de los municipios turísticos litorales, consolidada en el último período de incremento generalizado de la construcción de viviendas (1998-2007), se ha convertido en una de las principales trabas para la renovación y diversificación de los destinos maduros (Simancas, 2016, p. 16), lo mismo que a la hora de integrar los cada vez más valorados aspectos ambientales y de afrontar el reconocimiento y la puesta en valor del patrimonio territorial de estos entornos costeros.

A la habitual contraposición entre turismo de naturaleza y turismo inmobiliario vienen a sumarse los efectos negativos del llamado turismo residencial, ampliamente documentados (Navalón, 1999; Aledo, 2008; Burriel, 2014) como son los procesos especulativos, la gradual obsolescencia de los alojamientos edificados, la competencia desleal que estos suponen para la oferta reglada, la escasa generación de empleos fuera del sector de la construcción y la habitual escasez o ausencia de servicios complementarios.

A todo ello, cabe añadir el fenómeno en aumento del alquiler de viviendas de uso turístico mediante las denominadas plataformas peer to peer $(\mathrm{P} 2 \mathrm{P})$, en un contexto carente de control y regulación, que ha dado en denominarse con la equívoca expresión de economía colaborativa (Miralles y Villar, 2016) y que representa un serio obstáculo para la oferta reglada de establecimientos hoteleros y apartamentos turísticos ${ }^{5}$. Según ha señalado Aledo $\left(2008\right.$, p.102) ${ }^{6}$, la Comunidad autónoma con mayor número de viviendas de uso turístico en España es la Comunidad Valenciana (que ya en 2005 habría alcanzado más de 1,5 millones de viviendas potenciales de uso turístico), seguida de Andalucía (con 1,2 millones para el mismo año) y Cataluña (con 0,99 millones en la misma fecha).

Ciertamente, una primera constatación es la dificultad de contabilizar, a escala municipal, provincial o autonómica, el volumen real de viviendas de uso turístico (en propiedad, de familiares o amigos, en alquiler,...), muy superior al de la clasificación censal

3 Torrevieja es el municipio español que concentra, muy por encima del resto, el mayor número de segundas residencias: 62.585 según el Censo de Población y Viviendas de 2011, lo que equivale al 51,2\% del total de viviendas del municipio.

4 Recientemente, Mantecón (2017) ha cuestionado la utilización ideológica del término turismo residencial por parte de agentes interesados en hacer pasar por desarrollo turístico lo que es, esencialmente, negocio inmobiliario.

5 El Censo de Población y Viviendas 2011, dentro de la sección de "rankings municipales", aporta un listado de los cincuenta municipios españoles con mayor porcentaje de viviendas en alquiler, predominando los catalanes, baleares y canarios. En los primeros puestos de este listado, con más del 33\%, se hallan los municipios de Eivissa, Lloret de Mar y Yaiza.

6 Apoyándose en un estudio de Exceltur (2005): Impacto de los modelos de desarrollo turístico en el litoral mediterráneo y las Islas, Madrid, Deloitte-Exceltur. 
de viviendas secundarias ${ }^{7}$, como se comprueba para los tres principales casos citados y como varios autores han puesto de manifiesto (López y Módenes, 2004; Delgado, 2008a) ${ }^{8}$.

En 2015, Exceltur ${ }^{9}$ llevó a cabo un estudio sobre los efectos (sociales, económicos y fiscales, entre otros) del alquiler de viviendas turísticas de corta duración en España, actividad favorecida por los nuevos canales de comercialización y las plataformas tecnológicas ${ }^{10}$. El estudio se basó en la selección de veintidós destinos principales que, a su vez, fueron agrupados en doce destinos urbanos ${ }^{11} \mathrm{y}$ diez destinos vacacionales ${ }^{12}$. Pese a las dificultades para la cuantificación exacta, la estimación de plazas de alojamiento en viviendas de alquiler turístico, efectuada para finales de 2014 a escala española, llegaba a los 2,7 millones y su porcentaje sobre el total de la oferta turística (52\%) superaba al de la oferta de plazas en establecimientos reglados (Exceltur, 2015, p.11). Estas circunstancias atañen sobre todo a los principales destinos turísticos del litoral español y la demanda mayoritaria está compuesta por turistas extranjeros. No obstante, se trata de un proceso en expansión que afecta, cada vez, a un número mayor de áreas, puesto que una parte considerable de las viviendas alquilables va sumándose a esta opción altamente lucrativa ${ }^{13}$.

En relación con este contexto general de turismo inmobiliario que caracteriza a los municipios litorales españoles, el caso de estudio que hemos elegido para este artículo constituye un ejemplo interesante, puesto que reúne diversos rasgos comunes con otros destinos y algunas cualidades particulares o específicas, como es su localización en el litoral cantábrico. Asimismo, otro aspecto llamativo de este caso de estudio es que, aun-

7 En el Proyecto Censal de 2011, la vivienda secundaria se incluye dentro de los diferentes tipos de viviendas familiares convencionales (estos son: "viviendas principales", "viviendas secundarias", "viviendas vacías" y "viviendas de otro tipo"): La vivienda familiar convencional "Si ésta destinada a ser ocupada sólo ocasionalmente (por ejemplo durante las vacaciones) se denomina vivienda secundaria". A su vez, sobre las llamadas "viviendas de otro tipo" se indica que pueden ser "por ejemplo, viviendas destinadas a alquileres sucesivos de corta duración", pero el Censo de 2011 apenas aporta cifras a escala municipal dentro de esta categoría.

8 Según el Censo de 2011, en la Comunidad Valenciana se contabilizan 655.137 viviendas secundarias; 628.703 en Andalucía y 470.081 en Cataluña. Por provincias, los valores más altos se hallan en Alicante con 326.705 viviendas secundarias, Valencia con 223.885 y Málaga con 170.438 , seguidas de otras provincias de litoral mediterráneo como Barcelona (151.335), Girona (141.700), Tarragona (140.549), Murcia (132.216) y Castellón (104.547). En la costa norte, cantábrica y atlántica, La Coruña acumula los valores más elevados (86.193) junto con Cantabria (74.697) y Asturias (73.250).

9 Asociación no lucrativa, creada en 2002 y formada por más de una veintena de empresas líderes relacionadas con la actividad turística en España. La referencia completa de dicho estudio se cita en la bibliografía de este artículo.

10 Con un crecimiento espectacular entre la demanda extranjera a partir de 2011, año en el que empezaron a operar con fuerza en España los principales portales on-line especializados en el alquiler turístico (Exceltur, 2015, p.10).

11 Esto es: Barcelona, Madrid, Sevilla, Málaga, Valencia, Palma de Mallorca, Granada, Alicante, San Sebastián, Las Palmas de Gran Canaria, Bilbao y Santiago de Compostela.

12 Calvía, Benidorm, Lloret de Mar, Marbella, Salou, Adeje, San Bartolomé de Tirajana, Torremolinos, Playa de Palma y Peñíscola.

13 "El 93\% de la oferta de viviendas para turistas en España está dirigida a su alquiler a cambio de una contraprestación económica que se sitúa muy por encima de la del alquiler de larga estancia a residentes" (El Mundo, 12 de junio de 2016). En el caso de Cantabria no se ha realizado ningún estudio específico, pero algunas fuentes estiman que existen cerca de 3.000 viviendas turísticas de alquiler, siendo los municipios costeros donde se produce una mayor concentración (Diario Montañés, 22 de octubre de 2017). 
que se trata de un ejemplo notorio de especialización dentro del designado como turismo residencial, de manera reciente también se está dando en él el desarrollo de actividades de turismo de naturaleza, planteadas como complemento de las anteriores formas de negocio inmobiliario. Todas estas características y circunstancias se analizan en los siguientes apartados.

\section{NOJA, LA CONFIGURACIÓN DE UN MUNICIPIO TURÍSTICO-RESIDEN- CIAL EN LA COSTA CANTÁBRICA}

El municipio de Noja, con una superficie de apenas $9,2 \mathrm{kms}^{2}$, se sitúa en el litoral oriental de Cantabria, a 43 kilómetros al Este de Santander y a unos 75 al Oeste de Bilbao, fácilmente accesible por la autovía A8 ó del Cantábrico. Cuenta con casi 12 kilómetros lineales de costa, de los que más del $50 \%$ son extensiones de playa arenosa ${ }^{14}$. Otro aspecto notable es que el 75,4\% de la superficie municipal está incluida dentro del Parque Natural de las Marismas de Santoña, Victoria y Joyel, aunque dicha extensión protegida perteneciente al municipio tan solo representa en torno al $11 \%$ del total del Parque ${ }^{15}$.

Según el Padrón Municipal, a finales de 2016, en Noja se contabilizaban tan solo 2.562 habitantes $^{16}$, aunque habitualmente en los meses de verano la población estacional que se concentra en el municipio llega a ser de más treinta veces superior ${ }^{17}$. En relación con esta marcada variación estacional de población, otro dato significativo es que, según el Censo de Población y Viviendas de 2011, se trata del municipio español con mayor porcentaje de viviendas secundarias sobre el global de viviendas contabilizadas. Esto es nada menos que el $91 \%$ (véase el segundo gráfico de la figura 1). Dicho valor relativo es un síntoma innegable de la importancia alcanzada en las últimas décadas por el llamado turismo residencial, muy vinculado al proceso de expansión inmobiliaria desplegado en Noja a partir de los años ochenta, como se trata con detalle más adelante. Todo ello hace del municipio un caso paradigmático a escala española, con la peculiaridad añadida de situarse en la costa cantábrica, donde las condiciones para un turismo de sol y playa son mucho menos apropiadas que en el Mediterráneo.

14 Al noroeste del municipio y en la margen derecha de la ría de Quejo, se sitúa la playa de Ris, con una extensión de 2,2 kilómetros y una anchura media de 100 metros, mientras que al sureste de Noja, entre Punta Cañaverosa y la Punta del Brusco, se encuentra la playa de Trengandín, de 3,7 kilómetros y una anchura media de 200 metros. Ambas fueron galardonadas en 2014 con la "Q" de Calidad Turística (Catálogo de playas, Guía de playas. Ministerio de Agricultura, Pesca, Alimentación y Medio Ambiente, Gobierno de España. Recuperado de http://www.mapama.gob.es/es/costas/servicios/guia-playas/).

15 Declarado inicialmente Reserva Natural por la Ley 6/1992, de 27 de marzo, derogada por la Sentencia del Tribunal Constitucional 105/1998, de 1 de octubre y más tarde, declarado Parque Natural por la Ley 4/2006, de 19 de mayo, de Conservación de la Naturaleza de Cantabria (BOE, 3 de agosto de 2006).

16 Entre el año 2000 y 2012 la población residente en Noja creció en un 31,4\%, mientras que la de Cantabria lo hizo en un $11,8 \%$. A partir de 2013 y coincidiendo con los momentos más álgidos de la crisis, en ambos casos, Cantabria y Noja, se ha producido un descenso paulatino de la población residente que, comparando dicho año con los últimos datos de 2016, ha sido del $-1,7 \%$ y del $-2 \%$ respectivamente.

17 Según la Encuesta de Infraestructuras y Equipamientos Locales, elaborada el año 2000 por la Dirección General de Cooperación Local (Secretaría de Estado de Cooperación Territorial, Ministerio de Administraciones Públicas), en 1999 la población de Noja era de 1.981 habitantes y la estimación de población estacional máxima de 60.000 personas. 
Bien es cierto que este porcentaje tan elevado al que acabamos de hacer referencia se matiza con la cifra exacta de 10.815 viviendas secundarias registradas en 2011. Estas cantidades absolutas sitúan a Noja en el puesto $n^{\circ} 46$ del conjunto de municipios españoles con más de dos mil habitantes, ordenados de mayor a menor según el número de viviendas secundarias ó en el $\mathrm{n}^{\circ} 30$, si solo tenemos en cuenta aquellos que tienen más del $25 \%$ de su total de viviendas clasificadas como secundarias (cf. primer gráfico de la figura 1). No obstante, si de nuevo a partir de la interpretación de la información proporcionada por el Censo de Población y Viviendas de 2011, comparamos los datos municipales del total de viviendas con los del número de habitantes, Noja vuelve a ocupar el primer lugar a escala española, en una proporción que llega a las 4,5 viviendas existentes en el municipio por cada residente habitual ${ }^{18}$.

\section{Figura 1}

\section{LA SEGUNDA RESIDENCIA A ESCALA MUNICIPAL EN ESPAÑA, 2011}

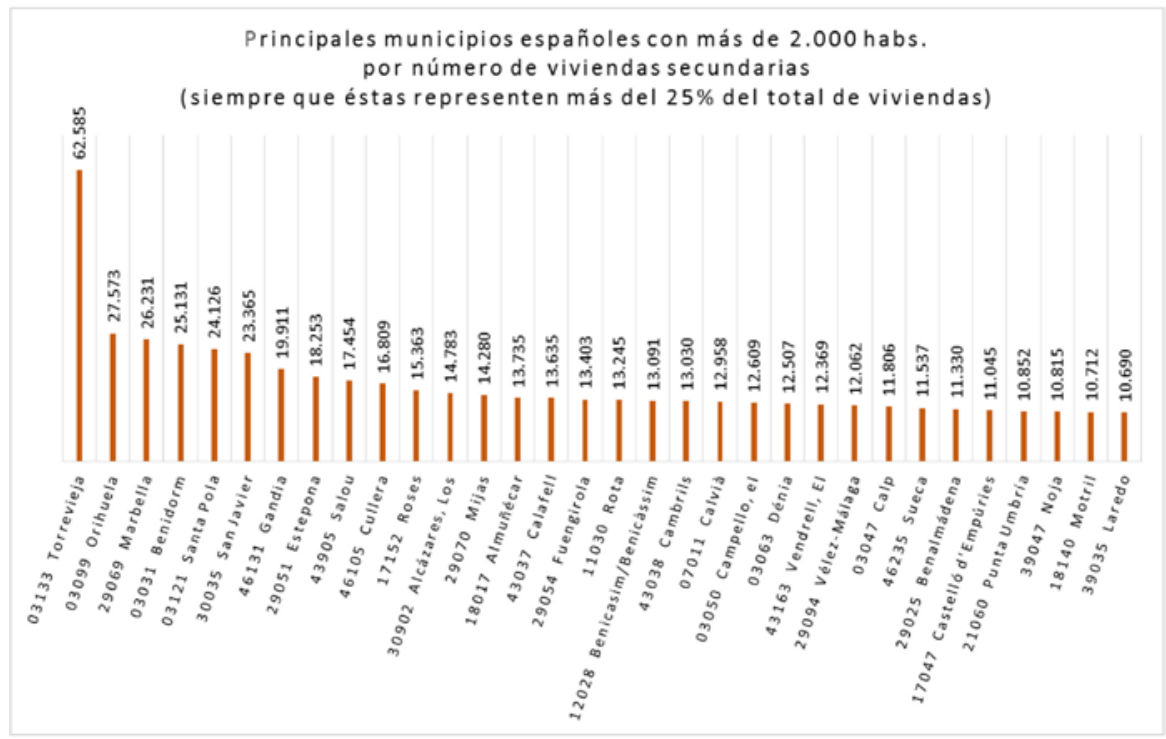

18 Los siguientes valores más altos a escala española son los de Castelló d'Empúries, Torrevieja, Santa Pola y Laredo, todos ellos con una proporción de 1,4 viviendas por habitante. 


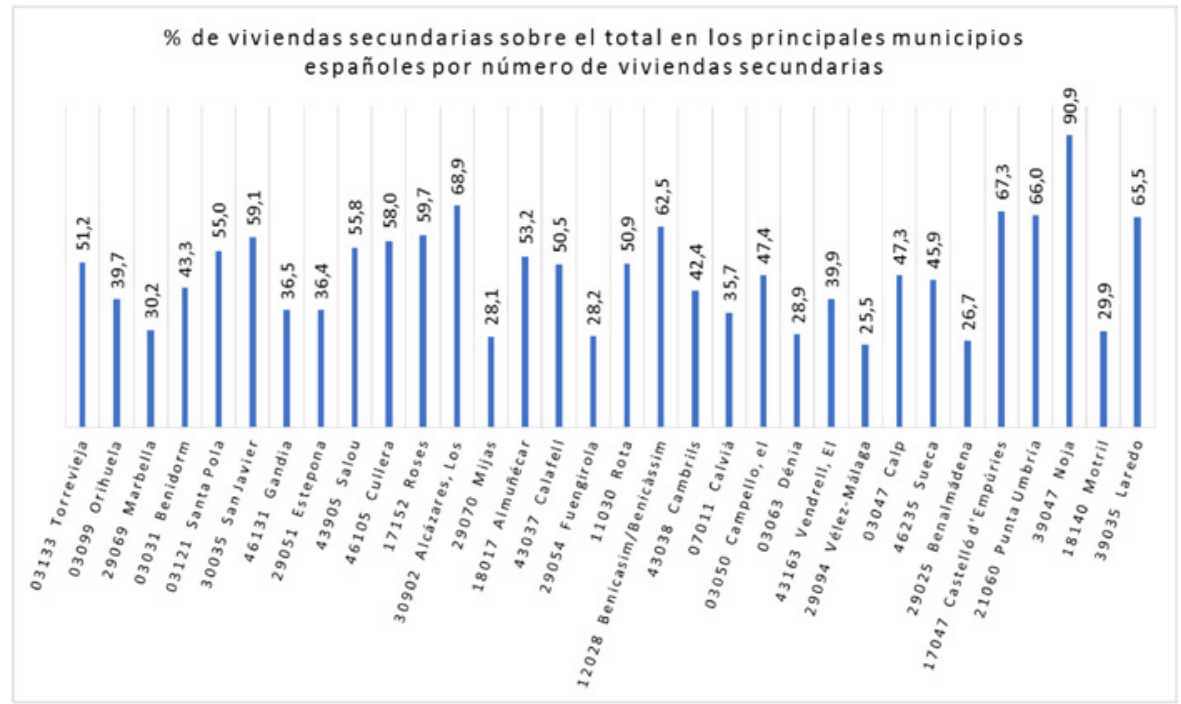

Fuente: Censo de Población y Vivienda de 2011; elaboración propia.

En cualquier caso, no es de extrañar que, dentro del conjunto de municipios de Cantabria, Noja ocupe el sexto lugar por número de titulares registrados en el Catastro de bienes inmobiliarios urbanos, con datos de $2017^{19}$ y la octava posición por valor catastral total, con datos de 2016. De hecho, conforme al Censo de 2011, las viviendas secundarias del municipio de Noja representan el 14,5\% del todas las existentes en Cantabria, porcentaje muy similar al de Laredo con el 14,3\% y superior incluso al de Santander y Castro-Urdiales (que aglutinan, respectivamente, el 11,1\% y el 11,5\% de las viviendas secundarias contabilizadas en la región).

En definitiva, todos estos diferentes valores numéricos confirman la fuerte especialización de este municipio de la Marina oriental de Cantabria en el turismo inmobiliario-residencial. Algo que también demuestran su propia fisionomía (figura 2) que ha experimentado un cambio radical en comparación con los años sesenta, y la actual clasificación urbanística del suelo (figura 3). Así, en el informe de Prieto y Ruiz (2013, p.182) realizado para Greenpeace España con datos de 2005, Noja aparece como el cuarto municipio de Cantabria con mayor superficie artificial en la franja de 500 metros de distancia respecto al borde de costa, al alcanzar 120 hectáreas urbanizadas (el 32\% de dicha franja), solo por detrás de Santander, Castro-Urdiales y Santoña.

19 Con exactamente 17.953 titulares. Esta cifra sitúa a Noja tan solo por detrás de la capital de Cantabria, Santander, y de los otros cuatro municipios con mayor desarrollo urbano de la región como son Torrelavega, Castro Urdiales, Laredo y Camargo (cf. Catastro urbano, Dirección General del Catastro, Ministerio de Hacienda y Administraciones Públicas, Gobierno de España). 
Figura 2

ESTADIOS DE EVOLUCIÓN DEL SUELO URBANO DE NOJA: 1960, 1981 Y 2017

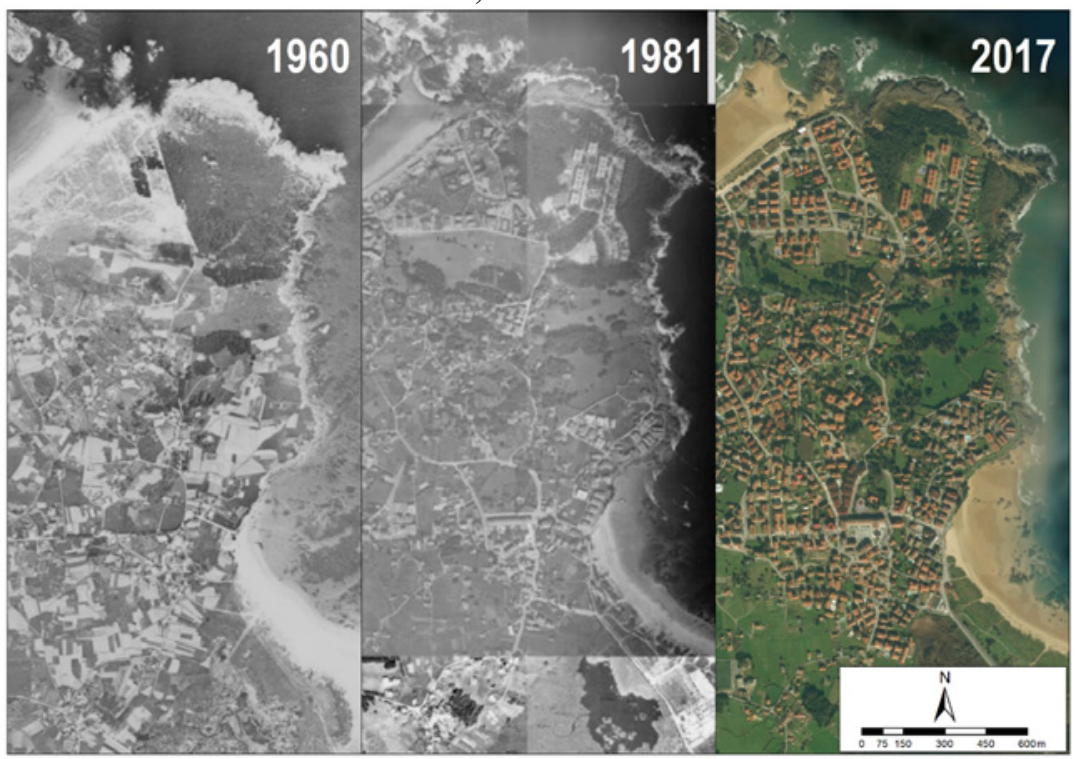

Fuente: Datos del Gobierno de Cantabria, en mapas.cantabria.es, y Esri, DigitalGlobe, GeoEye, Earthstar Geographics, CNES/Airbus DS, USDA, USGS, AEX, Getmapping, Aerogrid, I GN, IGP, swisstopo and the GIS User Community.

\section{Figura 3 \\ NOJA, CLASIFICACIÓN URBANÍSTICA DEL SUELO}

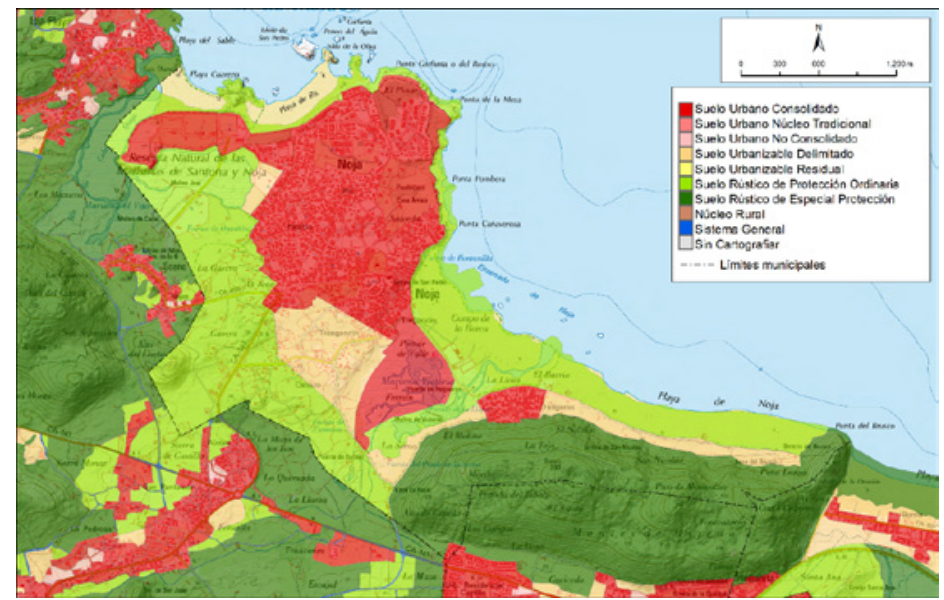

Fuente: Gobierno de Cantabria-IGN; datos del SIUCAN (Sistema de Información Urbanística de Cantabria). 


\subsection{El contexto de la especialización turístico-residencial}

En buena medida, la especialización turístico-residencial de Noja se explica por la proximidad geográfica del área metropolitana de Bilbao, de donde procede gran parte de los residentes temporales del municipio, propietarios de segundas viviendas.

Continuando con el análisis de la información proporcionada por el Censo de 2011, en lo que se refiere al colectivo de personas residentes en viviendas principales que disponen de otra vivienda en un segundo municipio, se desprende que el 18,3\% de la población de Vizcaya dispone de una segunda vivienda en otro municipio distinto al de su lugar habitual de residencia ${ }^{20}$. A escala provincial española, este porcentaje es el segundo más alto, a poca distancia del de Madrid (18,7\%). A su vez, Cantabria se encuentra entre los valores más bajos (con solo un 7,3\%).

Algunos municipios vizcaínos, en concreto, superan ampliamente el porcentaje provincial, como es el caso del propio Bilbao con un 22,5\% u otros de dicho área urbana como Derio (23,2\%), Basauri (22,3\%), Etxebarri $(21,4 \%)$, Arrigorriaga $(20,8 \%)$, Getxo $(20,6 \%)$, Sestao (19,9\%), Alonsotegui (19,9\%), Leioa (19,5\%), Portugalete (19,5\%), Barakaldo $(19,3 \%)$, Laukiz $(18,6 \%)$ y Galdakao $(18,6 \%)$.

En cuanto a la ubicación geográfica de estas segundas residencias, la comunidad autónoma donde mayor número de personas domiciliadas en Vizcaya poseen una segunda vivienda es Castilla y León, con el 21,7\% de los que en 2011 disponían de una segunda residencia, seguida de Cantabria con el 13,4\%. Además, el 10,2\% de estos dueños de segundas viviendas afincados en Vizcaya tiene su propiedad secundaria en algún otro municipio del País Vasco y hasta un 12,5\% en el extranjero. Sin embargo, a escala provincial, es en Cantabria donde mayor volumen de residentes en Vizcaya posee una segunda vivienda, con un total de 59.085 personas según el mencionado Censo de 2011, seguida de Burgos (44.165) y de la propia Vizcaya (31.770).

En el caso de los residentes en el municipio de Bilbao, los valores son de nuevo más altos que para el conjunto provincial, ya que el 17,6\% de los bilbaínos que cuentan con una segunda vivienda tienen su propiedad en algún municipio de Cantabria.

Otro aspecto importante para entender cómo se ha desarrollado la especialización residencial de Noja es el marco normativo y en particular, el planeamiento urbanístico municipal. La evolución de dicho marco regulador ha sido considerablemente compleja y conflictiva. Así, la figura todavía vigente hoy en día son las Normas Subsidiarias tipo B (art. 91-b del RD 2159/1978) aprobadas el 12 de julio de 1990 y publicadas en el BOC el 9 de octubre de dicho año, con sucesivas modificaciones, esencialmente encaminadas a habilitar suelo urbanizable. Sin embargo, ya en 2005, el Ayuntamiento puso en marcha un proceso de contratación con la finalidad de elaborar un Plan General de Ordenación Urbana (PGOU) para el municipio. Los pliegos de condiciones fueron aprobados en sesión plenaria municipal celebrada el 18 de abril de dicho año ${ }^{21}$.

20210.540 personas sobre un total de 1.150 .040 .

21 El 18 de mayo de 2005 se publican en el BOC, la aprobación, la exposición pública del pliego de cláusulas administrativas particulares y el anuncio de concurso para la redacción del Plan General de Ordenación Urbana del municipio de Noja. 
En noviembre de 2010 se instruyó el expediente de evaluación ambiental del futuro PGOU, con la recepción en la Consejería de Medio Ambiente, Ordenación del Territorio y Urbanismo del Gobierno de Cantabria de la memoria inicial del PGOU. A finales de 2012, tras varias correcciones, la documentación del expediente de evaluación ambiental fue remitida al público interesado y a las administraciones competentes, entre ellas la Demarcación de Costas de Cantabria. Este organismo señaló ${ }^{22}$ que el PGOU de Noja debía prever las necesarias reservas de suelo y los mecanismos urbanísticos adecuados para la reubicación de determinados elementos, situados dentro del actual dominio público marítimo-terrestre y que habían sido construidos con anterioridad al deslinde efectuado conforme a la vigente Ley de Costas. En concreto, estos elementos en situación irregular son tres campings (los denominados "Playa Joyel" y "Suaces" ambos dentro del sistema de dunas de la playa de Ris y "Los Molinos" sobre la marisma de Joyel); la carretera de acceso desde estos campings a la playa de Ris, que pasa por la citada marisma; el hotel "Los Tamarises" levantado en el sistema dunar de la playa de Trengandín; un campo de fútbol también construido sobre las dunas de dicha playa; la carretera de Noja a Helgueras y la pista de Helgueras al Brusco, así como los aparcamientos colindantes a estas dos vías de circulación, los cuales también afectan a dicho conjunto dunar. Todos estos elementos, a pesar de hallarse fuera de ordenación, siguen existiendo en la actualidad.

Es más, desde 2014 hasta ahora, la tramitación del PGOU se halla paralizada u oficialmente en estado de revisión, toda vez el 20 de febrero de dicho año fuera publicado en el BOC el anuncio de exposición pública de los presupuestos iniciales y orientaciones básicas (el avance) del PGOU, cuyo plazo fue ampliado más tarde, hasta el 1 de abril (BOC, 17 de marzo de 2014). En junio de 2015, como resultado de las elecciones municipales y de los acuerdos tomados entre los partidos políticos participantes, se produjo un cambio en la composición del equipo de gobierno del Ayuntamiento de Noja. Más recientemente, en 2017, el Consejo de Estado, supremo órgano consultivo del Gobierno de España, procedió a incoar, a propuesta de los grupos municipales que desde 2015 gobiernan en coalición, un expediente relativo a varios contratos irregulares suscritos por la anterior corporación. Entre los contratos investigados estaba el adjudicado en noviembre de 2005 a una empresa para efectuar labores de consultoría y asistencia técnica encaminadas a la redacción del PGOU. La resolución del Consejo de Estado dictaminó que procedía resolver el citado contrato (El Diario digital Cantabria, 2 de septiembre de 2017) e indemnizar a la empresa por las labores efectuadas hasta la fecha ${ }^{23}$. Así pues, cabría decir que actualmente el PGOU de Noja, después de más de una década de demora en su aprobación, se encuentra en una situación de impasse, algo que no es inhabitual en otros municipios españoles con circunstancias similares.

22 Informe de 14 de diciembre de 2012, recogido en el anexo II de la resolución de 30 de enero de 2013 de la Dirección General de Ordenación del Territorio y Evaluación Ambiental Urbanística, del Gobierno de Cantabria.

23 Consejo de Estado, dictámenes: Expediente instruido por el Ayuntamiento de la Villa de Noja relativo a "Resolución del contrato de consultoría y asistencia técnica en la redacción del Plan General de Ordenación Urbana del Municipio de Noja”. Referencia 363/2017. Fecha de aprobación 29/6/2017. 


\subsection{Las características de la expansión turístico-inmobiliaria: un fenómeno tempo- ralmente concentrado y explosivo}

Junto con este contexto, conviene tener en cuenta cómo se ha materializado, a lo largo del tiempo, el proceso de expansión inmobiliaria y de crecimiento urbano de Noja. Una vez más, este proceso puede considerarse análogo al de otros muchos municipios costeros españoles, aunque con rasgos distintivos de unos casos a otros. En Cantabria, los ejemplos más intensivos de crecimiento urbanístico litoral se sitúan en esta parte oriental de la región, más próxima al País Vasco (Delgado, 2008b). Además, es en toda esta franja que va desde Ribamontán al Mar hasta Castro Urdiales donde se encuentran las cifras absolutas más elevadas y algunos de los mayores porcentajes de viviendas secundarias sobre el total de viviendas familiares de la región (figura 4).

Analizando cronológicamente este proceso a partir del Censo de 2011, se observa que en torno a una cuarta parte de las viviendas actuales del municipio de Noja se han construido ya entrado el siglo XXI (figura 5). En concreto, para este período, la etapa de edificación más acelerada fue la de los años 2002, 2003 y 2004, durante los cuales se construyeron en Noja 1.640 viviendas, es decir el 13,8\% de todas las viviendas con las que cuenta el municipio en la actualidad. No obstante, a partir de 2005 el proceso de construcción se ralentiza progresivamente, de forma que, en los dos últimos años recogidos por dicho Censo, los de 2010 y 2011, no se registra ninguna nueva vivienda construida, coincidiendo con el mayor rigor de la crisis del sector de la construcción en toda España y con una saturación de la oferta inmobiliaria existente en el municipio.

\section{Figura 4 \\ VIVIENDAS SECUNDARIAS EN LOS MUNICIPIOS DE CANTABRIA: PORCENTAJE SOBRE EL TOTAL DE VIVIENDAS DE CADA MUNICIPIO}

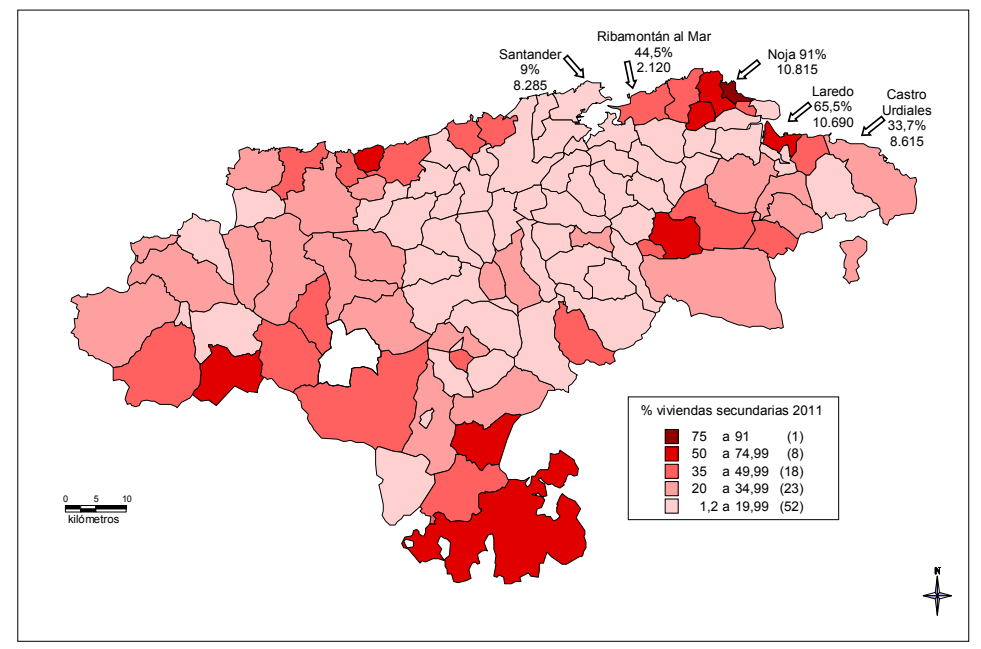

Fuente: Censo de Población y Viviendas, 2011, INE. Viviendas, resultados municipales. 
Previamente, los períodos más intensos de construcción de viviendas en Noja habían sido el de los años 1981 a 1990 y sobre todo, el de 1991 a 2001. En ambas décadas, ochenta y noventa, se construye casi el $70 \%$ de las viviendas actuales, destinadas en su gran mayoría a una demanda externa, es decir no censada en el municipio. Así, conforme a los datos del INE, en la primera de estas etapas, la de los años ochenta, el 91,7\% de las viviendas construidas se inscriben en la categoría de no principales, mientras que durante la segunda etapa, la de los noventa, las viviendas no principales alcanzaron el $95,8 \%$ del total de viviendas construido (figura 6).

Por el contrario, en las décadas de los sesenta y setenta, cuando se inicia la expansión inmobiliaria en España, todavía eran pocas las viviendas que se construían en Noja, que mantenía aún un marcado carácter rural: sólo el 5,1\% de todas las viviendas con las que cuenta el municipio en la actualidad se levantan durante ambas décadas, mientras que en el conjunto de Cantabria las viviendas de este período ascienden hoy en día al 25,4\% del total (Figura 5). Incluso, si nos remontamos a períodos anteriores, el número de viviendas edificadas en Noja en la primera mitad del siglo XX es todavía menor: ni siquiera llegan al $1 \%$ de las actuales.

Confirmando lo anterior, según el Censo de 2011, la edad media de las viviendas de Noja es de menos de 18 años y, en concreto, la antigüedad media de las viviendas secundarias no llega a los 17 años. Estos valores son los más bajos de la región, de manera que el conjunto de viviendas del municipio es el de menor edad media de toda Cantabria.

\section{Figura 5}

\section{EVOLUCIÓN CRONOLÓGICA EN LA CONSTRUCCIÓN DE VIVIENDAS EN NOJA Y EN CANTABRIA}

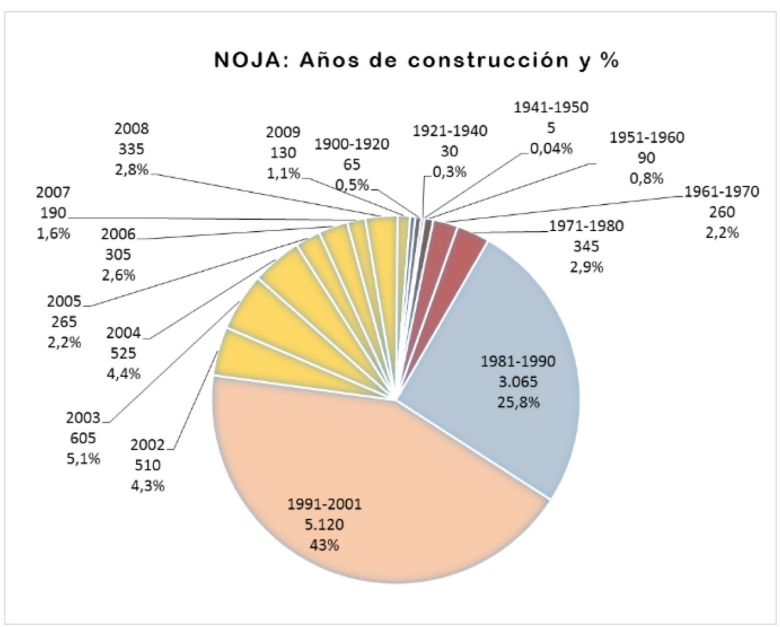




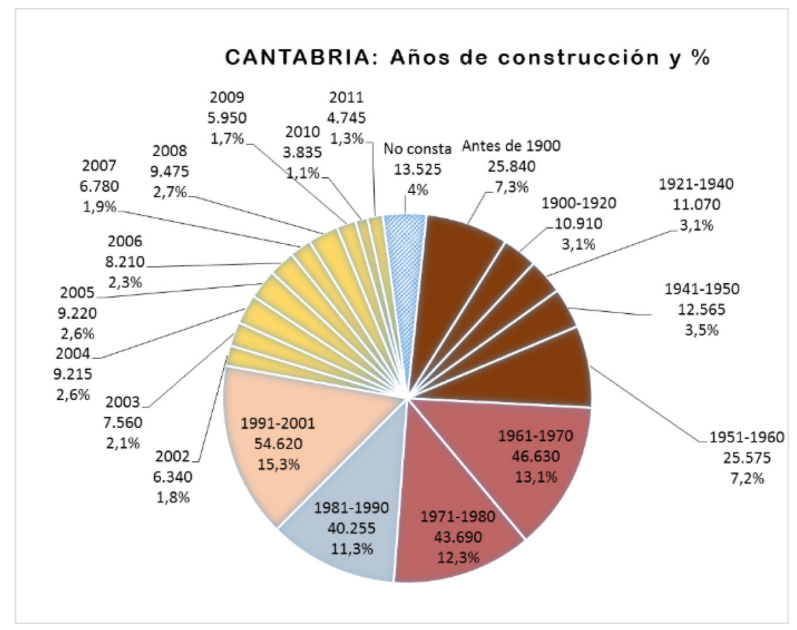

Fuente: Censo de Población y Viviendas, 2011. INE; elaboración propia.

Ello nos indica que el boom inmobiliario en Noja es comparativamente más reciente que en otros municipios de Cantabria donde el fenómeno también ha sido notable, como Laredo o Castro Urdiales, o más concentrado en el tiempo, puesto que arranca sobre todo a partir de los años ochenta. A pesar de ello, en un relativamente breve lapso de tiempo, el proceso ha llegado a ser de los más intensos a escala regional y de toda la costa cantábrica ${ }^{24}$, con una orientación casi exclusiva hacia la edificación de viviendas para uso no principal (figura 6), marcada por una fuerte estacionalidad, lo que hace que buena parte del año sea frecuente la característica imagen de "persianas bajadas" y de establecimientos cerrados.

Respecto a la tipología constructiva, predominan en Noja los edificios de tres, cuatro o cinco plantas, siendo estos últimos los que aportan el mayor volumen de viviendas (figura 7). Por su parte, para la década de 1998 a 2008, la cifra media por edificio construido ha sido de 18 de viviendas, mientras que en cuanto a superficie para el mismo período, el promedio ha sido de 117,5 metros cuadrados por vivienda ${ }^{25}$.

Por lo demás, no existe en Noja ningún edificio de viviendas con más de cinco plantas sobre rasante, a diferencia de lo que sucede en otros municipios próximos como Argoños, Ribamontán al Mar, Santoña, Castro Urdiales o Laredo ${ }^{26}$. Sin embargo, los edificios de viviendas de una o dos plantas son escasos, concentrando menos del $6 \%$ del total de las viviendas actuales (figura 7).

Coincidiendo con la lentificación reciente en la construcción de viviendas, ya constatada a partir del Censo de Población y Viviendas de 2011, también las cifras referidas a las

24 Según el cálculo efectuado a partir de los datos de construcción de edificios, recopilados por el área de Fomento del Gobierno de España y proporcionados por el ICANE, entre 1998 y 2015 se construyeron en Noja 523 viviendas por kilómetro cuadrado, la proporción a escala municipal más alta de toda Cantabria.

25 Elaborados a partir de la información sobre Construcción de edificios, datos municipales. Área de Fomento, Gobierno de España, Delegación del Gobierno en Cantabria (1998-2016), ICANE.

26 El caso de Laredo es llamativo ya que el 59,3\% del total de viviendas se hallan en edificios con seis plantas o más; incluso el 29,4\% de las viviendas del municipio se sitúan en edificios de diez o más plantas. 
licencias municipales de obras, proporcionadas por el área de Fomento del Gobierno de España, indican que entre 2009 y 2016 prácticamente no se han tramitado licencias para edificios residenciales en Noja (únicamente aparecen registradas tres licencias para otros tantos edificios residenciales, en los años 2010, 2012 y 2015 respectivamente ${ }^{27}$ ). Incluso antes de esta paralización constatada a partir de 2009, se había iniciado ya una tendencia descendente. Así, de la cifra record alcanzada con las licencias de obra tramitadas en el año 2000, que permitieron la construcción de 1.437 viviendas distribuidas en 68 edificios de nueva planta y un total de 167.344 metros cuadrados, se pasa a una media anual de 222 viviendas y 26.463 metros cuadrados entre 2001 y 2008.

\section{Figura 6}

\section{VIVIENDAS NO PRINCIPALES SEGÚN PERÍODO O FECHA DE CONSTRUCCIÓN}

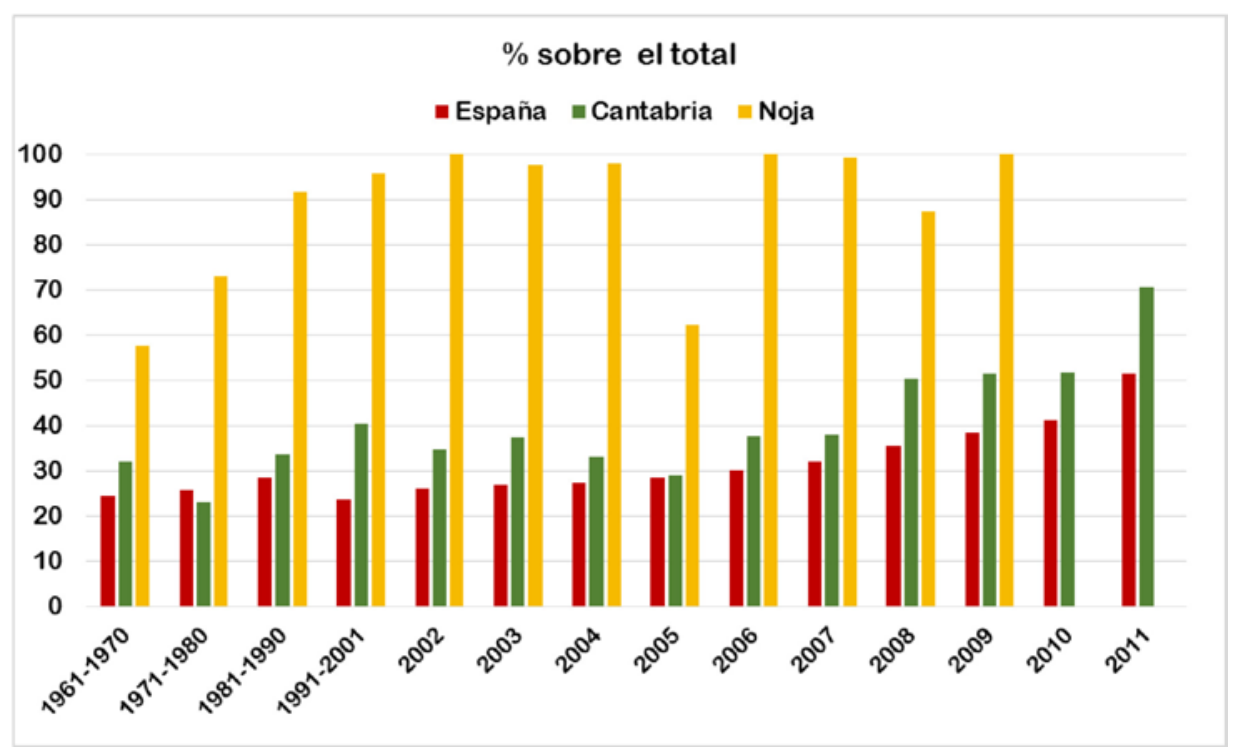

Fuente: Censo de Población y Viviendas, 2011. INE; elaboración propia.

27 Además, las edificaciones de los años 2010 y 2012 fueron ambas para viviendas unifamiliares, mientras que la de 2015 permitió la construcción de un edificio de once viviendas. 


\section{Figura 7 \\ VIVIENDAS EN NOJA SEGÚN NÚMERO DE PLANTAS SOBRE RASANTE}

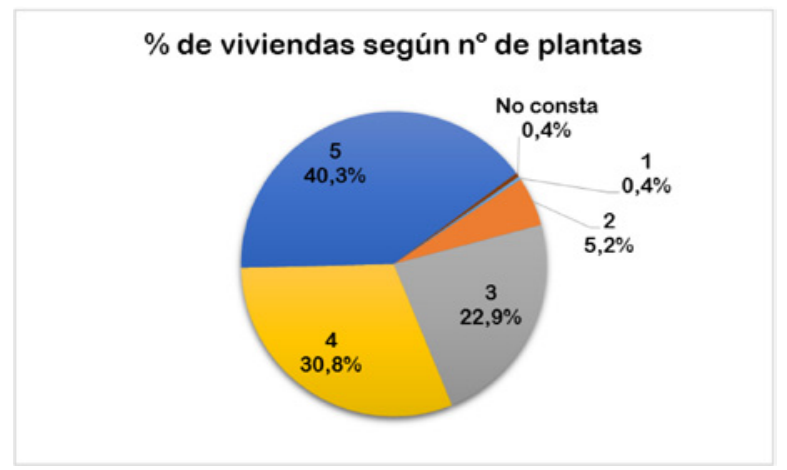

Fuente: Censo de Población y Viviendas, 2011. INE; elaboración propia.

Como hemos apuntado anteriormente, este receso en la construcción de viviendas en Noja se enmarca dentro del contexto general de crisis de la actividad inmobiliaria y de la construcción en España, iniciada en los años 2007-2008 y vinculada, a su vez, con la crisis del sistema financiero mundial (Rodríguez, 2017). Conjuntamente, en el caso de Noja parece evidente que, con una oferta total de 11.800 viviendas de las que sólo un 8,4\% son principales, se ha llegado a una saturación en la ocupación de suelo y en la oferta inmobiliaria del municipio, muy por encima de las necesidades de la población residente y de la capacidad física para seguir creciendo.

Pero tales circunstancias van más allá y reflejan el agotamiento del modelo de desarrollo económico seguido en Noja a partir de los años ochenta. Como se ha ido analizando en este artículo, dicho modelo, semejante al de otros municipios litorales españoles (López y Pérez, 2017), ha estado centrado en el incremento de la superficie ocupada por los conjuntos residenciales de uso turístico ${ }^{28}$, al margen de otros aspectos como la oferta de servicios complementarios o la puesta en valor del patrimonio natural y cultural ${ }^{29}$. Como en muchos otros lugares, el objetivo ha sido construir el máximo número de viviendas y venderlas, con independencia de su ocupación posterior. El cuestionamiento del modelo y la búsqueda de alternativas podrían suponer un punto de inflexión sobre cuyas características y potencialidades se reflexiona en el siguiente apartado.

28 Según el Directorio de Empresas y Establecimientos de Cantabria (ICANE), a 31 de diciembre de 2015, de los 196 establecimientos registrados en Noja, 49,7\% llevaban a cabo actividades de construcción o inmobiliarias; $14,4 \%$ eran establecimientos de comercio minorista, $10,5 \%$ servicios de alojamiento y $12,2 \%$ se dedicaban a hostelería y restauración. En la gran mayoría de casos, sin asalariados o con menos de nueve empleados (sólo dos establecimientos, uno de construcción y otro de alojamiento tenían entre diez y diecinueve empleados).

29 Bien es cierto que en Noja no se ha llegado a la situación conflictiva de otros municipios cántabros, como Arnuero, Argoños y Escalante, donde el Tribunal Superior de Justicia de Cantabria (TSJC) ha dictado sentencias de derribo de edificios de viviendas construidos dentro de los límites del Parque Natural de las Marismas de Santoña, Victoria y Joyel. 


\section{LA APUESTA RECIENTE POR UN TURISMO DE NATURALEZA.}

Turismo inmobiliario y turismo de naturaleza son considerados, a priori, dos formas opuestas y por tanto difícilmente compatibles. Sin embargo, la presencia de un espacio natural protegido próximo a una zona de amplio desarrollo turístico y urbanístico crea relaciones subjetivas entre ambas modalidades de turismo, como han mostrado Romagosa y Cuadrado (2008) para el caso del Alt Empordà en la Costa Brava, y Capdepón (2010) para el de las Salinas de Santa Pola en Alicante, ambos caracterizados por la presencia de humedales, como también sucede en Noja.

Por otra parte, según Blázquez-Salom (2007), para el mercado, los espacios naturales son, sobre todo, nuevos productos de consumo ${ }^{30}$. En el mismo sentido crítico se han manifestado más recientemente otros autores como Büscher y Fletcher (2017). Así pues, dentro de la óptica productiva capitalista, el turismo de naturaleza o en espacios naturales protegidos no solo resulta en la práctica complementario al turismo inmobiliario-residencial (por muy contradictorio que ello pueda parecer conceptualmente), puesto que permite la generación de capital, sino que además cuenta con el atractivo de presentarse, discursivamente (es decir desde el punto de la percepción y de la creación de representaciones sociales), como una modalidad más respetuosa con la conservación y de menor impacto ambiental, lo que conlleva una evidente mejora de la imagen turística y refuerza aún más el consumo, en una espiral de intereses que se retroalimentan (Gil de Arriba, 2018).

\subsection{Recursos naturales y figuras de protección}

A partir de estas consideraciones generales, cabe recordar que el Parque Natural de las Marismas de Santoña, Victoria y Joyel, con cerca de 70 kilómetros cuadrados de extensión, distribuidos a lo largo de once municipios de la costa oriental de Cantabria, entre los que se encuentra el de $\mathrm{Noja}^{31}$, se crea en 2006, dentro de la propia Ley de 19 de mayo, de Conservación de la Naturaleza de Cantabria. Previamente, en 1992, estos tres espacios marismeños, mencionados en la denominación del Parque y que actualmente forman un todo conjunto, fueron declarados Reserva Natural ${ }^{32}$. La sucesiva implantación de éstas y otras figuras de protección en el área ${ }^{33}$ no ha estado, en absoluto, exenta de controversias y ni de conflictos de intereses y de uso. A comenzar por la sentencia del Tribunal de Justicia de las Comunidades Europeas (TJCE) de 2 de agosto de 1993 que condenaba a España por no respetar las directi-

30 Según el análisis esclarecedor de este autor "Los espacios naturales no pueden asegurar la conservación de los ecosistemas [...] ante las actuales amenazas de deterioro ambiental. Para conseguirlo, se debe modificar el sistema productivo, económico y social” (Blázquez-Salom, 2007). Proceso que, evidentemente, va mucho más allá de lo que actualmente se entiende por turismo de naturaleza, inserto, como el resto de prácticas turísticas, dentro del mismo modelo productivo capitalista, en busca de mayor rentabilidad y mayores beneficios.

31 Dos de los elementos que dan nombre a este Parque se hallan en Noja: la marisma Victoria, pequeño lago salobre junto a la playa y dunas de Trengandín, se encuentra enclavada en su totalidad dentro del municipio, mientras que el humedal de Joyel, delimitado por la playa de Ris, el monte Castrejón y la ría de Quejo, se distribuye entre los municipios de Noja y Arnuero.

32 La extensión protegida inicialmente dentro de la Reserva era casi la mitad del actual Parque, unas 3.500 hectáreas.

33 En agosto de 1994 se creó la ZEPA ES0000143 y en octubre de ese mismo año se produjo la declaración como humedal Ramsar. Ya en 2004, se crea el LIC ES1300007. 
vas comunitarias de protección de las aves silvestres y de hábitats naturales. Dicha sentencia y todas las circunstancias que condujeron a ella (Gil de Arriba, 2013) son una muestra del lento y complejo proceso de toma en consideración, medioambiental y socioeconómica, de los espacios naturales en España y más en particular, de los humedales, desde finales de los años ochenta. Asimismo, otra prueba de estas dilaciones para nuestro caso de estudio en concreto es que tras la aprobación tardía del PORN, en mayo de $1997^{34}$, su revisión posterior no se emprende hasta 2009, hallándose todavía en proceso en la actualidad ${ }^{35}$.

A pesar de todas estas circunstancias ${ }^{36}$, a lo largo de estos veinticinco años desde la declaración de la Reserva Natural, el proceso seguido para la restauración y la progresiva puesta en valor de este espacio natural de alto valor ecológico también ha servido para despertar un interés creciente por las nuevas oportunidades de actividad económica vinculadas con la preservación ambiental y el desarrollo sostenible. En este sentido, paulatinamente se han ido introduciendo nuevas tendencias relacionadas con el uso público y la sensibilización medioambiental. Así, mientras que, en un principio, la creación del espacio protegido fue vista con desconfianza por parte de varios sectores de población, principalmente los propietarios del suelo y los vinculados con las actividades inmobiliarias, con el tiempo estas interpretaciones contrapuestas se han ido matizando, puesto que la figura de protección ha desencadenado nuevas dinámicas. En concreto, el Parque Natural se ha convertido en un nuevo y apreciable recurso turístico e incluso en un referente a escala regional y de toda la cornisa cantábrica, para la atracción de demanda.

\subsection{Los nuevos referentes turísticos asociados a la naturaleza}

Las demandas turísticas y recreativas tienen una creciente influencia en las dinámicas territoriales y socioeconómicas de los espacios naturales protegidos. Uno de los aspectos principales de la gestión de estos espacios es la ordenación de su uso público ${ }^{37}$. Inicial-

34 El PORN debería haber sido aprobado antes de la declaración de la Reserva Natural, conforme a la Ley 7/1989 de 27 de marzo, de Conservación de los Espacios Naturales y de la Flora y Fauna Silvestre, entonces en vigencia. Como la Reserva fue declarada por vía de urgencia, mediante la Ley 6/1992, de 27 de mayo, esta misma Ley de declaración estableció el plazo excepcional de un año para la aprobación del PORN. Este plazo se incumplió puesto que el PORN fue realmente aprobado por el Decreto del Gobierno de Cantabria 34/1997, de 5 de mayo.

35 La Ley 4/2006 de 19 de mayo, de Conservación de la Naturaleza en Cantabria, en su disposición final segunda establecía que, en el plazo de un año desde su entrada en vigor, debía iniciarse el proceso de revisión de PORN de 1997 y en el plazo de dos años desde la aprobación del nuevo PORN, debía elaborarse el Plan Rector de Uso y Gestión (PRUG). Este último es todavía inexistente. Con respecto a la revisión del PORN, en junio de 2014, el Patronato del Parque Natural aprobó un documento inicial para su exposición pública. Sin embargo, la cantidad de alegaciones presentadas han retardado ampliamente la aprobación definitiva por parte del Consejo de Gobierno de Cantabria.

36 De las que, con mayor o menor grado de similitud, podemos encontrar ejemplos comparables en otros espacios protegidos españoles, como el del Parque Natural de los Aiguamolls de l'Empordà, estudiado por los ya citados Rimagosa y Cuadrado (2008) quienes en su trabajo explican cómo algunas regiones mediterráneas han perdido más del $60 \%$ de la superficie de sus humedales a lo largo del siglo XX, mientras que los movimientos de salvaguarda, por parte de grupos ecologistas y por parte de la administración pública no se han planteado hasta finales de siglo.

37 Europarc-España (2002, p.82) define el uso público de un espacio protegido como "el conjunto de actividades, servicios y equipamientos que, independientemente de quien los gestione, debe proveer la administra- 
mente, la noción de uso público hacía referencia estricta a la interpretación y a la educación ambiental. Sin embargo, en la actualidad, junto con estas funciones, las actividades de ocio tienen cada vez mayor relevancia, lo que está claramente relacionado con que el conocimiento y el disfrute de la naturaleza se han convertido en productos de consumo (Gil de Arriba, 2014).

A escala autonómica, en España existen situaciones variadas en la planificación y gestión del uso público de los espacios naturales protegidos, como desde hace más de una década viene señalando la sección española de la Federación de Parques Naturales y Nacionales de Europa (Europarc). Según esta misma fuente, donde más se ha avanzado en la elaboración de modelos de uso aplicados a sus respectivas redes de espacios protegidos ha sido en Andalucía, Canarias y Cataluña (Europarc-España, 2012). En el caso de Cantabria, la protección de los espacios naturales muestra todavía carencias y deficiencias, con escasos instrumentos disponibles o con un uso inapropiado de los mismos, esto es favorable a los intereses inmobiliarios (Delgado, 2012). Por su parte, otros países de nuestro entorno próximo como Francia, con el ejemplo de los parques naturales regionales iniciados en los años sesenta, cuentan con una amplia experiencia en materia de protección y dinamización (Boschet y Rambonilaza, 2010).

En lo referente a Noja, una muestra de esta capacidad de atracción del espacio natural se observa en el incremento constante de la cifra de visitantes del llamado Molino de las Aves en la marisma Victoria, del barrio de Helgueras. En el mes de julio de 2017, momento de máxima afluencia turística anual al municipio, el citado centro de interpretación medioambiental recibió la cifra record hasta la fecha de 2.668 visitantes, un $8 \%$ más que en el mismo mes de 2016, en su mayoría procedentes del País Vasco y en menor medida de la Comunidad de Madrid (Diario Montañés, 22 de agosto de 2017) ${ }^{38}$.

El Molino de las Aves fue inaugurado en 2013, tras la rehabilitación de un antiguo molino de mar o de mareas cuyos orígenes datan del siglo XVII ${ }^{39}$. La restauración del molino se realizó en $2006^{40}$. Más tarde, el acondicionamiento como centro de observación de aves fue llevado a cabo por el Ayuntamiento de Noja en colaboración con SEO/ BirdLife, con quien en abril de 2012 se firmó un convenio destinado a favorecer la observación y el conocimiento de las especies de aves presentes en las marismas. A partir del verano de dicho año, se emprendió una campaña de promoción del turismo ornitológico.

ción del espacio protegido con la finalidad de acercar a los visitantes a sus valores naturales y culturales, de una forma ordenada, segura y que garantice la conservación y la difusión de tales valores a través de la información, la educación y la interpretación ambiental".

38 Las declaraciones del concejal de medioambiente de Noja al proporcionar estos datos al periódico resaltaron "la intención del equipo de gobierno en potenciar los valores naturales del municipio como atractivos turísticos y complemento ideal a la tradicional oferta de sol y playa", lo que directamente coincide con esta búsqueda de complementariedad entre ambos modelos de turismo.

39 Fue declarado Bien de Interés Cultural en la categoría de monumento por decreto del Gobierno de Cantabria 134/2002, de 31 de octubre.

40 En dicho año, los distintos municipios por los que se extiende el Parque manifestaron la necesidad de creación de un centro de interpretación del humedal (Diario Montañés, 25 de noviembre de 2006). En la actualidad, el principal Centro de Interpretación del Parque Natural de las Marismas de Santoña, Victoria y Joyel, también llamado El Mirador de las Marismas, se encuentra en Santoña, en la zona del puerto pesquero y fue abierto en agosto de 2009. El primer año completo de funcionamiento, 2010, recibió 31.121 visitantes (Diario Montañés, 14 de marzo de 2011). 
Al mismo tiempo, dentro del eje ambiental del Plan de Competitividad Turística del municipio se empezaron a ejecutar actuaciones para potenciar esta modalidad turística, como la señalización y el balizamiento de itinerarios, la edición de una guía de aves, la organización de encuentros con ornitólogos de prestigio o la realización de cursos para agentes turísticos. Inicialmente se pensó en la construcción de una torre de observación de aves junto al molino Victoria o cerca de la playa de Trengandín, pero finalmente se optó por adecuar para este uso el restaurado molino. Según el propio Ayuntamiento, en los tres primeros años de funcionamiento, el Molino ha recibió más de dieciséis mil visitantes (4.810 en $2014,5.351$ en 2015 y 6.208 en 2016).

En la actualidad, el centro de las Aves permanece abierto a lo largo del año con distintas actividades de ecoturismo, entre las que se halla un programa de rutas guiadas por los distintos ecosistemas del municipio y cursos, talleres y conferencias de formación medioambiental. Ha sido distinguido como Centro Azul por la FEE (Foundation for Environmental Education), gracias a sus prácticas de educación ambiental y es miembro de la red SICTED de Calidad en Destino, promovida por la Secretaría de Estado de Turismo y la Federación Española de Municipios y Provincias. Además, este tipo de actividades ornitológiccas, cada vez más habituales en el conjunto de municipios que integran el Parque, permiten una relativa desestacionalización de la afluencia turística, ya que buena parte se desarrollan en los meses de otoño y primavera, coincidiendo con los ciclos migratorios de las aves. Al mismo tiempo también han contribuido a la creación de algunas pequeñas empresas de ámbito local ${ }^{41}$.

En este sentido, en los últimos años, frente al patrón expansivo del turismo inmobiliario-residencial, ha empezado a plantearse un nuevo interés por la puesta en valor de los recursos naturales del municipio de Noja: playas, dunas, arenales, humedales, zonas de arbolado y de matorrales boscosos, praderas, etc ${ }^{42}$. Con anterioridad a la apertura del Molino de las Aves, las visitas guiadas para conocer el patrimonio natural de Noja comenzaron en 2006, coincidiendo con la declaración del Parque y en un principio fueron organizadas a través de la Agencia de Desarrollo Local y Medio Ambiente, dependiente del Ayuntamiento, principalmente entre escolares de la región, aunque progresivamente la oferta se ha ido destinando cada vez más a la demanda turística. Así, otros organismos que sucesivamente ha ofertado rutas guiadas por las Marismas de Santoña, Victoria y Joyel han sido la Mancomunidad de Municipios Sostenibles (MMS) ${ }^{43}$, en virtud de un convenio con la Consejería de Desarrollo Rural, Ganadería, Pesca y Biodiversidad para

41 Por citar un ejemplo, a finales de septiembre de 2017, tuvo lugar la undécima edición del llamado Festival de la Migración de las Aves, organizado por una de estas recientes empresas especializadas en actividades ambientales, y apoyado por la Consejería de Medio Rural, Pesca y Alimentación de Cantabria y el Ayuntamiento de Santoña, con manifestaciones en los municipios de Santoña, Noja, Arnuero y Colindres. Por su parte, Noja organizó en octubre de 2017 la I Feria Internacional del Ecoturismo ECONoja, con la participación de profesionales y empresas del sector y de organismos públicos vinculados al medio rural.

42 Por otra parte, también se han puesto en valor los componentes arquitectónicos y culturales, ya que, a comienzos de 2011, el Ayuntamiento de Noja aprobó un Plan Especial de Protección y Catálogo de Edificios Singulares, con un total de cincuenta edificios públicos o privados catalogados, tanto civiles como religiosos, además de los conjuntos urbanos y varios elementos como fuentes y puentes.

43 Constituida en 2000 y actualmente formada por un total de 16 municipios de Cantabria, entre los cuales se halla Noja. 
promover el uso público en la Red de Espacios Naturales Protegidos de Cantabria, y el proyecto Naturea-Cantabria ${ }^{44}$.

Además, en relación con estos itinerarios medioambientales de uso turístico (Doctor, 2011) en 2010, a escala de la Comunidad autónoma y a cargo del Gobierno de Cantabria, fue aprobado el Plan especial de Sendas y Caminos de Litoral (PESC) ${ }^{45}$. Entre sus objetivos está la integración del litoral de la región en el proyecto de sendero europeo GRE-9 ó de la Cornisa Cantábrica. En lo que respecta al municipio de Noja, tres son las sendas contempladas por dicho Plan, incluidas dentro de la categoría de Gran Recorrido Litoral (GRL). De Este a Oeste, la primera discurre de la playa de Berria (Santoña) al núcleo de Helgueras, con una longitud de casi 5 kilómetros; la segunda enlaza Helgueras con la playa de Ris, a lo largo de 3,5 kilómetros y finalmente, la tercera de 4 kilómetros conecta dicha playa con la localidad de Soano y el Ecoparque de Trasmiera, en el municipio de Arnuero.

Asimismo, en los últimos años, Noja ha venido participando como municipio turístico en distintas ferias promocionales como Expovacaciones en Bilbao y Fitur en Madrid. Así, además de la formación medioambiental, el turismo ornitológico y el senderismo, otros elementos de turismo activo por los que se ha optado para el cambio de imagen del municipio son actividades deportivas como el surf, el kaya surf y el parapente. Ello coincide con la construcción en 2007 de un centro de ocio municipal con instalaciones para actividades deportivas, y de un campo de golf de nueve hoyos, ambos próximos a la playa de Ris.

\section{CONCLUSIONES. ¿SON COMPATIBLES AMBAS OPCIONES? ¿ES POSIBLE UN CAMBIO REAL DE MODELO?}

Este apartado final de conclusiones se enuncia a modo de dos interrogantes, diseccionando la cuestión formulada en un principio, en el propio título del artículo. Ahora ya, después de haber llevado a cabo el análisis pormenorizado del caso de estudio propuesto. La primera de estas dos nuevas preguntas retoma la posibilidad de coexistencia entre turismo inmobiliario-residencial y turismo de naturaleza, como dos formas o modalidades turísticas que puedan, en la práctica, llegar a complementarse funcionalmente en un mismo territorio, algo que, pese a parecer teóricamente contradictorio y plantear una indudable complejidad inicial, parece resultar hoy en día factible según se desprende del ejemplo abordado. Todo ello enlaza con la creciente utilización ideológica y publicitaria de determinados términos o eslóganes turísticos entre los que cabe incluir los de turismo residencial (Mantecón, 2017), turismo de naturaleza (Blázquez-Salom, 2007) y turismo sostenible (Fletcher, 2011), aunque en realidad la mayoría de actuaciones llevadas a cabo disten de ser ecológicas o sostenibles. Se trata por tanto no de una compatibilidad real

44 El proyecto Naturea-Cantabria se crea con el fin de promover actividades de uso público y sensibilización ambiental en los espacios naturales protegidos de la Comunidad autónoma y es gestionado desde 2008 por la Red Cántabra de Desarrollo Rural. En el caso de Noja, a través de Naturea se han venido desarrollando visitas guiadas por las playas de Ris y Trengandín y la marisma de Joyel.

45 Decreto 51/2010, de 26 de agosto. El PESC tiene su origen en la Ley 2/2004, de 27 de septiembre, del Plan de Ordenación del Litoral (POL) que en su artículo 67 señala la necesidad de realizar dicho Plan especial. 
(auténtica), sino discursiva (retórica) a partir de lemas o tópicos que aúnan bajo un mismo modelo de consumo una serie de códigos sociales, económicos e ideológicos impuestos por los grupos dominantes y asumidos por el conjunto de la población, como elementos sutiles de alienación.

La segunda pregunta, derivada de la inicial, es más global y hace referencia a cómo el turismo se integra hoy en día dentro de los patrones de evolución de la sociedad capitalista y del libre mercado. En una etapa aguda de crisis socioeconómica y de paralización de la construcción de viviendas, como la experimentada en España en los últimos años (Burriel, 2014), la búsqueda de alternativas, reales o figuradas (una vez más discursivas), al turismo inmobiliario, una de las formas más negativas del turismo de masas y más depredadoras de recursos y de territorio, se ha planteado como un imperativo forzoso. Así, cada vez más, la actividad turística trata de reforzar su imagen como actividad económica respetuosa con el medio ambiente, capaz de generar empleos, bienestar y alternativas de desarrollo socioeconómico. Y ello no solamente para captar demanda, sino también para evitar, en aquellas zonas donde se ha producido una saturación excesiva, caer en la impopularidad desde el punto de vista de los residentes, provocando reacciones en cadena de "turismofobia" (Huete y Mantecón, 2018).

Compatibilizar, en el sentido de hacer coexistir, ambas opciones, turismo inmobiliarioresidencial y turismo de naturaleza, es posible en la práctica, por extraño que el binomio parezca. Lo hemos constatado para un municipio de apenas 9,2 kilómetros cuadrados que, por un lado, alcanza los porcentajes más altos para toda España de viviendas no principales sobre el total de viviendas y que, por otro, cuenta con $3 / 4$ de su superficie declarada espacio natural protegido, lo que más allá de ser un elemento formal en la ordenación de usos del suelo, permite llevar a cabo la promoción reciente de un turismo ecológico (en septiembre de 2018 se ha llevado a cabo la II Feria Internacional de Ecoturismo Noja). La coexistencia de ambas prácticas turísticas, residencial (inmobiliaria) y de naturaleza, es factible porque, en realidad, ambas formas de turismo, por muy contrapuestas que puedan parecer a priori, son distintas opciones de mercado, correspondientes con diferentes etapas de evolución dentro de una misma economía capitalista. Es decir no suponen realmente, tal como se plantean y llevan a cabo actualmente, un verdadero cambio del modelo productivo dominante. Es más, en el caso de Noja, los beneficios previamente generados por las licencias de obras y la recalificación urbanística pueden ser aplicados hoy en día, paradójicamente, para promover el turismo de naturaleza, por parte del propio Ayuntamiento o de asociaciones locales de empresarios.

A escala global, cuestionar en profundidad el modelo de desarrollo turístico actual, sus diferentes productos y tipologías mediante actividades realmente alternativas supondría ir más lejos de la mera promoción de prácticas de turismo de naturaleza, tal y como son enfocadas a día de hoy (como un producto más para incrementar la demanda y el consumo). Como plantea Fletcher (2011) en su análisis crítico del turismo internacional y de las contradicciones intrínsecas del ecoturismo, ello equivaldría a desafiar las bases del sistema productivo capitalista centrado en anteponer el beneficio económico y el crecimiento constante. La aventura es sin duda más osada. 


\section{REFERENCIAS BIBLIOGRÁFICAS}

ALEDO TUR, A. (2008): «De la tierra al suelo: la transformación del paisaje y el nuevo turismo residencial», Arbor: ciencia, pensamiento y cultura, n 729, pp. 99-113.

BLÁZQUEZ-SALOM, M. (2007): «Los espacios naturales, "El mango de la sartén va al otro lado"», Scripta nova. Revista de Geografía y Ciencias Sociales. XI, 245(37). Disponible en http://www.ub.edu/geocrit/sn/sn-24537.htm

BOSCHET, C. y RAMBONILAZA, T. (2010): «Les mécanismes de coordination dans les réseaux sociaux : un cadre analytique de la dynamique territoriale», Revue d'économie régionale et urbaine, $\mathrm{n}^{\mathrm{o}} 3$, pp. 569-593. Disponible en http://www.cairn.info/revue-deconomie-regionale-et-urbaine-2010-3-page-569.htm

BURRIEL DE ORUETA, E.L. (2014): «El estallido de la burbuja inmobiliaria y sus efectos en el territorio», en J.M. Albertos Puebla y J.L. Sánchez Hernández (Coords.), Geografía de la crisis económica en España. Universitat de València, Servei de Publicaciones, pp. 101-140.

BÜSCHER, B. y FLETCHER, R. (2017): «Destructive Creation: Capital Accumulation and the Structural Violence of Tourism», Journal of Sustainable Tourism, 25(5), pp. 651-667.

CAPDEPÓN FRÍAS, M. (2010): «Desarrollo de la potencialidad turística del Parque Natural de las Salinas de Santa Pola (Alicante)», en D. López Olivares (Dir.), Turismo y gestión de espacios protegidos. XII Congreso Internacional de Turismo Universidad y Empresa. Valencia, Tirant lo Blanch, pp. 453-473

CAPDEPÓN FRÍAS, M. (2016): «Conflictos ambientales derivados de la urbanización turístico-residencial. Un caso aplicado al litoral alicantino», Boletín de la Asociación de Geógrafos Españoles, no 71, pp. 31-57.

DELGADO VIÑAS, C. (2008a): «Vivienda secundaria y turismo residencial como agentes de urbanización y segregación territorial en Cantabria», Scripta Nova. Revista Electrónica de Geografía y Ciencias Sociales, XII, 269. Disponible en http://www.ub.edu/ geocrit/sn/sn-269.htm\#_ednref2

DELGADO VIÑAS, C. (2008b): «Urbanización sin fronteras. El acoso urbanístico a los espacios naturales protegidos», Boletín de la Asociación de Geógrafos Españoles, $\mathrm{n}^{\circ}$ 47, pp. 271-310.

DELGADO VIÑAS, C. (2012): «Protección y ordenación del medio natural en Cantabria. Normativa, instrumentos y conflictos territoriales», Boletín de la Asociación de Geógrafos Españoles, $\mathrm{n}^{\circ}$ 60, pp. 115-140.

DOCTOR, A.M. (2011): «El itinerario como herramienta para la puesta en valor turístico del patrimonio territorial», Cuadernos de Turismo, $\mathrm{n}^{\circ}$ 27, pp. 273-289.

EXCELTUR (2015): Alojamiento turístico en viviendas de alquilar: Impactos y retos asociados. Impactos sociales y económicos sobre los destinos españoles derivados del exponencial aumento del alquiler de viviendas turísticas de corta duración, impulsado por los nuevos modelos y canales de comercialización P2P. Disponible en https:// www.exceltur.org/wp-content/uploads/2015/06/Alojamiento-tur\%C3\%ADstico-enviviendas-de-alquiler-Impactos-y-retos-asociados.-Informe-completo.-Exceltur.pdf 
EUROPARC-ESPAÑA (2002): Plan de acción para los espacios naturales protegidos del Estado español. Sección del Estado español de la Federación de Parques Naturales y Nacionales de Europa. Madrid, Fundación Fernando González Bernáldez.

EUROPARC-ESPAÑA (2012): Anuario 2011 del estado de las áreas protegidas en España. Sección del Estado español de la Federación de Parques Naturales y Nacionales de Europa. Madrid, Fundación Fernando González Bernáldez.

FLETCHER, R. (2011): «Sustaining tourism, sustaining capitalism? The tourism industry's role in global capitalism expansion», Tourism Geographies, 13 (3), pp. 443-461. GIL DE ARRIBA, C. (2013): «Les enjeux de la patrimonialisation du Parc naturel des Marais de Santoña, Victoria e Joyel (Cantabrie, Espagne)», Vertigo. La revue électronique en sciences de l'environnement, hors-série $\mathrm{n}^{\circ} 16$. Disponible en https://vertigo. revues.org/13647

GIL DE ARRIBA, C. (2014): «Protección, puesta en valor patrimonial y uso público de las marismas de Santoña, Victoria y Joyel (Cantabria). Dinámicas territoriales y socioeconómicas», en Jordá Borrel, R. et al. (Eds.), VI Jornadas de Geografía Económica: Dinámicas económicas y territoriales. Procesos globales y locales en el siglo $X X I$. Asociación de Geógrafos Españoles, Grupo de Geografía Económica, Centro de Ciencias Humanas y Sociales, CSIC, Universidad de Sevilla, pp. 343-363.

GIL DE ARRIBA, C. (2018): «Ecotourism and real-estate tourism. Dealing with contradictions in Spanish rural áreas: the case of two municipalities on the Cantabrian Coast», en E. Gómez Pellón, (Eds.), Rural Worlds, Social Sustainability and Local Landscapes in the Globalisation Era. Case Studies in Southern Europe. Aranzadi (Thomson Reuters), pp. 189-212.

HUETE NIEVES, R. y MAZÓN MARTÍNEZ, T.M. (2005): «Turismo residencial en el litoral alicantino: los casos de Denia, Altea, Benidorm, Santa Pola y Torreviega», en T.M. Mazón Martínez y A. Aledo Tur (Coords.), Turismo residencial y cambio social. Nuevas perspectivas teóricas y empíricas. Universidad de Alicante, pp. 105-138.

HUETE, R. Y MANTECÓN, A. (2018): «El auge de la turismofobia ¿hipótesis de investigación o ruido ideológico?», Pasos. Revista de Turismo y Patrimonio Cultural, $\mathrm{n}^{\circ}$ 16-1, pp. 9-19. Disponible en http://www.pasosonline.org/Publicados/16118/ PS118_01.pdf01.pdf

LÓPEZ COLÁS, J. y MÓDENES CABRERIZO, J.A. (2004): «Vivienda secundaria y residencia múltiple en España: una aproximación sociodemográfica», Scripta Nova. Revista Electrónica de Geografía y Ciencias Sociales, VIII, 178. Disponible en http:// www.ub.edu/geocrit/sn/sn-178.htm

LÓPEZ MARTÍNEZ, F. y PÉREZ MORALES, A. (2017): «Influencia del turismo residencial sobre el riesgo de inundación en el litoral de la región de Murcia», Scripta Nova. Revista Electrónica de Geografía y Ciencias Sociales, 21, 577. Disponible en http:// revistes.ub.edu/index.php/ScriptaNova/article/view/18166/22483

MANTECÓN, A. (2017): «El turismo residencial no existe. Revisión de un concepto y crítica de su función ideológica», Cuadernos de Turismo, n 40, pp. 405-422. Disponible en http://dx.doi.org/10.6018/turismo.40.310041 
MATEU I LLADÓ J. (2003): «Turismo residencial y dispersión urbana en Mallorca (Illes Balears). Un ensayo metodológico en el municipio de Pollença», Instituto de Estudios Turísticos, $\mathrm{n}^{\mathrm{o}}$ 155-156, pp. 197-218.

MAZÓN MARTÍNEZ, T.M. y ALEDO TUR, A. (2004): «La masificación del turismo residencial: el modelo de Torrevieja», en Turismo, ocio y deporte. VIII Congreso Español de Sociología. Universidad de Alicante, pp. 275-286.

MAZÓN, T., y ALEDO, A. (2005): «El dilema del turismo residencial: ¿turismo o desarrollo inmobiliario?», en T. Mazón (Ed.). Turismo residencial y cambio social. Nuevas perspectivas teóricas y empíricas. Universidad de Alicante, pp. 13-29.

MIRALLES MARUGÁN, P. y VILLAR LAMA, A. (2016): «Las viviendas de uso turístico: un análisis del conflicto», International Journal of World of Tourism, 3 (6), pp. 22-35.

MURRAY MAS, I. (2015): Capitalismo y turismo en España: del milagro económico a la gran crisis. Barcelona. Barcelona, Alba Sud. Colección Turismos. Prólogo de Macià Blàzquez Salom.

NAVALÓN GARCÍA, R. (1999): «Caracterización del espacio turístico residencial del litoral valenciano», Boletín de la Asociación de Geógrafos Españoles, n ${ }^{\circ} 28$, pp. 161-178.

NAVARRO JURADO, E. (2008): «La redefinición de un destino a partir del turismo residencial. El caso de la Costa del Sol», en S. Antón Clavé y F. González Reverté (Eds.), A propósito del turismo: la construcción social del espacio turístico. Editorial UOC, pp. 273-281.

PONCE SÁNCHEZ, M.D. (2010): «Percepción de los nuevos paisajes residenciales en el entorno del Mar Menor», Gran Tour, n 1, pp. 63-78.

PRIETO, F.; RUIZ, J.B. et al. (2013): Costas inteligentes, visión para un futuro sostenible en 2030. Madrid, Greenpeace España.

RODRÍGUEZ LÓPEZ, J. (2017): «Las viviendas que pudieron hundir la economía española. La caída del mercado de vivienda y sus consecuencias», Cuadernos de Relaciones Laborales, vol. 35, $\mathrm{n}^{\circ} 1$, pp. 71-99.

ROMAGOSA CASALS, F. y CUADRADO CIURANETA, S. (2008): «Turismo de naturaleza versus turismo residencial de masas. El caso del Alt Empordà (Costa Brava)», en Las administraciones públicas y empresas turísticas ante el reto de la sostenibilidad. XI Congreso AECIT, Paneles. Universidad Católica San Antonio de Murcia, Asociación Española de Expertos Científicos en Turismo, AECIT, 14 pp.

SERRANO MARTÍNEZ, J.M. (2007): «El turismo residencial en la Región de Murcia frente a los nuevos retos», Cuadernos de Turismo, nº 19, pp. 189-216.

SIMANCAS CRUZ, M.R. (2016): «Los procesos de residencialización de las áreas turísticas del litoral», en M.R. Simancas Cruz y J. Mañoso Valderrama, (Eds.), La residencialización de las áreas turísticas de Canarias. Las Palmas de Gran Canaria, Promotur Turismo, pp. 13-42.

VERA REBOLLO, F. (1984): «Mutaciones espaciales producidas por el turismo en el municipio de Torrevieja», Investigaciones geográficas, $\mathrm{n}^{\circ}$ 2, pp. 115-138.

VERA REBOLLO, F. y BAÑOS CASTIÑEIRA, C.J. (2010): «Renovación y reestructuración de los destinos turísticos consolidados del litoral: las prácticas recreativas en la evolución del espacio turístico», Boletín de la Asociación de Geógrafos Españoles, $\mathrm{n}^{\circ} 53$, pp. 329-353. 